\title{
Correction to: Large Group Decision Making
}

\section{Correction to:}

\section{Palomares Carrascosa, Large Group Decision Making,} SpringerBriefs in Computer Science, https://doi.org/10.1007/978-3-030-01027-0

This book was inadvertently published with wrong author names in Chaps. 2 and 4. Iván Palomares Carrascosa has now been rightly addressed as the author in these chapters and the research scholars have been acknowledged in the front matter.

\footnotetext{
The updated online version of this book can be found at https://doi.org/10.1007/978-3-030-01027-0_2 https://doi.org/10.1007/978-3-030-01027-0_4 https://doi.org/10.1007/978-3-030-01027-0 